\title{
Dopplerographic Assessment of Blood Flow \\ Parameters of Vertebral Arteries in Patients with Cervicogenic Headache Due to Arthrosis and Instability of Atlanto-Axial Junction
}

\author{
Abdullaiev R Ya*, Kalashnikov VI, Voronzhev IA, Sharmazanova EP, Kostyukovskaya AE and Abdullaiev RR \\ Department of Ultrasound Diagnostics, Kharkov Medical Academy of Postgraduate Education, Ukraine
}

Submission: March 26, 2018; Published: April 19, 2018

*Corresponding author: Rizvan Ya Abdullaiev, Department of Ultrasound Diagnostics, Kharkov Medical Academy of Postgraduate Education, Ukraine, Email: rizvanabdullaiev@gmail.com

\section{Abstract}

Introduction: Cervicogenic Headache $(\mathrm{CH})$ is a syndrome characterized by chronic hemicranial pain that is referred to the head from either bony structures or soft tissues of the neck. Factors such as:

i. Stable uncomfortable positioning of the head;

ii. Increased mobility of the upper cervical vertebrae with rotational movements;

iii. A combination of external pressure over the occipital region and mobility of the cervical vertebrae on the symptomatic side causes or strengthens the existing headache. The leading role in the formation of the central nervous system is played by the irritation of the vegetative plexus of the vertebral arteries.

Objective: Dopplerographic evaluation of blood flow parameters in vertebral arteries in patients with cervicogenic headache due to arthrosis and instability of the atlanto-axial junction.

Materials and methods: A retrospective analysis of the results of Doppler ultrasound in the $2^{\text {nd }}$ and $3^{\text {rd }}$ segments of the Vertebral Artery (VA) was performed in 58 patients aged 21-38 years, who had X-ray and MRI diagnosed arthrosis and instability of the atlanto-axial junction: among the examined were 21 men and 37 women. The maximum Systolic Velocity (Vs), the end Diastolic Velocity (Vd), the Resistance Index (RI) in second and third segments of VA in the neutral spine and flexion position of the neck. The control group consisted of 27 people aged 19-36 years without chronic headache, absence of arthrosis of the atlanto-axial junction according to the results of X-ray or MRI. Dopplerography was conducted on a Philips HD 11XE device using a linear and microconvection transducers in the frequency range 5-10MHz and 4-9 MHz; MRI General Electric, Signa HDI, 1.5T.

Results: In the control group in the second segment of the VA, Vs was $50.3 \pm 5.1 \mathrm{~cm} / \mathrm{s}, \mathrm{RI}-0.61 \pm 0.03$; at the level of $3^{\text {rd }}$ segment $-48.9 \pm 5.1 \mathrm{~cm} / \mathrm{s}$, RI - 0.58 \pm 0.03 ; at the rotation of the head - Vs $43.6 \pm 4.5 \mathrm{~cm} / \mathrm{s}$, RI - $0.62 \pm 0.03$, respectively. In a patients with Atlanto-axial arthrosis in the second segment of the VA, Vs was $48.9 \pm 5.3 \mathrm{~cm} / \mathrm{s}$, RI- $0.56 \pm 0.03$; at the level of $3^{\text {rd }}$ segment $-45.3 \pm 4.9 \mathrm{~cm} / \mathrm{s}, \mathrm{RI}-0.54 \pm 0.03$; at the rotation of the head$37.2 \pm 4.1 \mathrm{~cm} / \mathrm{c}, \mathrm{RI}-0.71 \pm 0.04(\mathrm{P}<0.05)$ respectively. In patients with atlanto-axial instability at the level of C5-C6, Vs amounted to $49.2 \pm 5.1 \mathrm{~cm} / \mathrm{s}$, RI-0.59 \pm 0.03 ; at the level of $3-d$ segment of VA-Vs was $46.1 \pm 4.8 \mathrm{~cm} / \mathrm{s}$, RI $-0.58 \pm 0.03$. When the head was turned to the side in patients with instability of the atlanto-axial junction, Vs was significantly lower compared to the control group $(34.1 \pm 4.2 \mathrm{~cm} / \mathrm{s}$ and $43.6 \pm 4.5 \mathrm{~cm} / \mathrm{s}$; RI more then in the second segment of the VA $(\mathrm{P}<0.05)$.

Conclusion: Instability of atlanto-axial junction, especially in combination with arthrosis, is one of the common causes of cervicogenic headache in young people. The main pathogenetic mechanism of the onset of pain is changes in blood flow in the third segment of the vertebral arteries, especially during rotational movements.

Keywords: Atlanto-axial junction, Dopplerography, Cervicogenic Headache, Atlanto-axial arthrosis \& instability; Vertebral artery; Sedentary; Pathogenetic; Migraine features; Phonophobia

Abbreviations: CH: Cervicogenic Headache; VA: Vertebral Artery; VD: Diastolic Velocity; RI: Resistance Index; CVMS: Cervical Vertebral Motor Segments; CHISG: Cervicogenic Headache International Study Group; NFR: Nociceptive Flexor Reflexes; VA: Vertebral Artery; RI: Resistance Index; RVAO: Rotational Vertebral Artery Occlusion 


\section{Introduction}

Cervicogenic Headache ( $\mathrm{CH}$ ) - one of the most common, is due to biomechanical dysfunction of the Cervical Vertebral Motor Segments (CVMS). It accounts for $15-20 \%$ of all headaches. More common in women (ratio 4: 1); occurs at any age, there is no hereditary predisposition, the course is predominantly chronic. The $\mathrm{CH}$, as a rule, suffer from representatives of "sedentary" occupations, as well as those who in the process of work often have to tilt their head or work with the dropped. Factors such as:

i. Stable uncomfortable positioning of the head;

ii. Increased mobility of the upper cervical vertebrae with rotational movements;

iii. A combination of external pressure over the occipital region and mobility of the cervical vertebrae on the symptomatic side causes or strengthens the existing headache. The leading role in the formation of the central nervous system is played by the irritation of the vegetative plexus of the vertebral arteries [1].

The current version of the diagnostic criteria of the $\mathrm{CH}$ is presented in the International Classification of HeadacheRelated Disorders (ICHRD-3 beta) in paragraph 11.2.1 (Table 1). According to ICHRD-3, CH is a headache caused by a lesion of the neck (bone structures, disc and/or soft tissues) and is usually accompanied by pain in the neck. The unilateral character of the headache without a change of sides, the provocation of a typical pattern of pain by the external pressure on the neck muscles or movement in the cervical spine, the spread of the pain from the occipital area to the front temporal allows differentiating $\mathrm{CH}$ from migraine and tension headache. Nevertheless, the $\mathrm{CH}$ may have some "migraine features", such as nausea, vomiting, photo and phonophobia, but their intensity and severity is significantly less than with migraine [2].

The leading pathogenetic mechanism of $\mathrm{CH}$ development is a change in the mobility of the three upper cervical segments. The leading role in the formation of the central nervous system is played by the irritation of the vegetative plexus of the vertebral arteries. There is a significant lack of agreement in the definition of the diagnosis of cervicogenic headache [3]. The $\mathrm{CH}$ diagnostic criteria rely, at least in part, on a patient's response to diagnostic facet injection blocks. Controlled diagnostic blocks into the cervical facet joints are invasive, expensive and not readily available, and so they cannot be considered as useful in most practitioners' offices. Merging the International Headache Society IHS and the Cervicogenic Headache International Study Group (CHISG) criteria helped improve the diagnosis of cervicogenic headaches [3].

There is considerable overlap in the clinical presentations of cervicogenic, migraine and tension-type headaches, implying that many of these signs and symptoms are not unique to any particular headache type. Because of these issues, according to Hall "incorrect headache diagnosis may occur in more than $50 \%$ of cases." Therefore, it is important that the practitioner carefully keep in mind competing diagnoses and monitor response to treatment [4].

The traditional diagnosis method of cervical spondylosis is based on X-ray reading. Based on an analysis of 1034 clinical cases and 60 cases of a test group using digital radiography [5] increased the diagnostic efficiency of up to $80 \%$ of cervical spondylosis compared with conventional radiography, which diagnosed spondylosis in $68.3 \%$ of cases [5].

Doppler ultrasound imaging is a noninvasive and useful modality for the examination of vertebral arteries. Color duplex/Doppler ultrasound is considered to provide a valid and reliable noninvasive measurement of vertebral arterial blood flow velocity. There is evidence that Doppler ultrasound measures of vertebral artery blood flow may be sufficiently responsive to detect changes in cervical rotations or after intervention. It has been reported that a decrease in vertebral artery blood flow could be identified by Doppler ultrasound at both upper and lower cervical levels during end-range cervical rotation in asymptomatic participants. This indicated that Doppler ultrasound would be able to detect changes in the vertebral arterial blood flow velocities decreased when the vertebral arteries are under stress from compression or stretching. Doppler ultrasound has also been used to detect improvement in vertebral arterial blood flow velocities in patients with vertebrobasilar artery insufficiency before and after medical intervention [5-8].

Based on the study of nictitating and nociceptive flexor reflexes (NR and NFR) in 63 patients with chronic and 40 patients with epizodic migraine, Zenkevich AS [9] concluded that in a large number of patients, neck pain is an indispensable component of the pathogenesis of chronic migraine [9].

\section{Objective}

Dopplerographic evaluation of blood flow parameters in vertebral arteries in patients with cervicogenic headache due to arthrosis and instability of the atlanto-axial junction.

\section{Materials and Methods}

A retrospective analysis of the results of Doppler ultrasound in the $2^{\text {nd }}$ and $3^{\text {rd }}$ segments of the Vertebral Artery (VA) was performed in 58 patients aged 21-38 years, who had X-ray and MRI diagnosed arthrosis (26 person) and instability (32 person) of the atlanto-axial junction; among the examined were 21 men and 37 women. The maximum Systolic Velocity (Vs), the end Diastolic Velocity (Vd), the Resistance Index (RI) in second and third segments of VA in the neutral spine and flexion position of the neck were determined. The control group consisted of 27 people aged 19-36 years without chronic 
headache, absence of arthrosis of the atlanto-axial junction according to the results of X-ray or MRI. Dopplerography was conducted on a Philips HD 11XE device using a linear and microconvection transducers in the frequency range $5-10 \mathrm{MHz}$ and 4-9 MHz; MRI - General Electric, Signa HDI, 1.5T.

\section{Results}

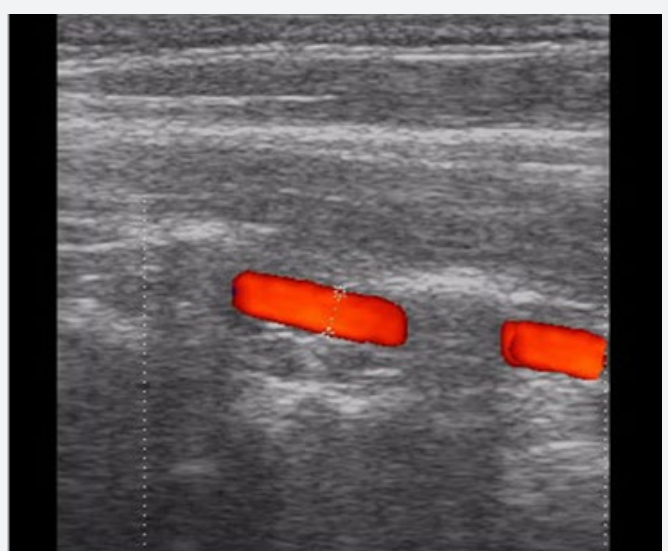

Figure 1: Color Doppler view of the normal vertebral artery at the second segment.

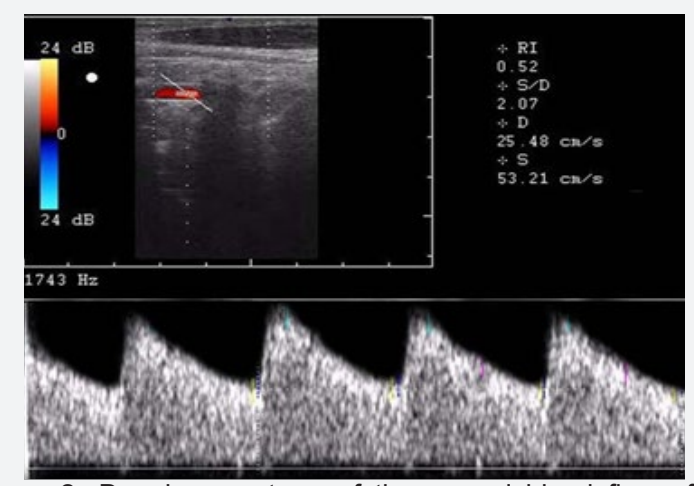

Figure 2: Doppler spectrum of the normal blood flow of the vertebral artery at the level of C4-C5. The Vs is $53.21 \mathrm{~cm} / \mathrm{c}, \mathrm{RI}$ -0.52 .

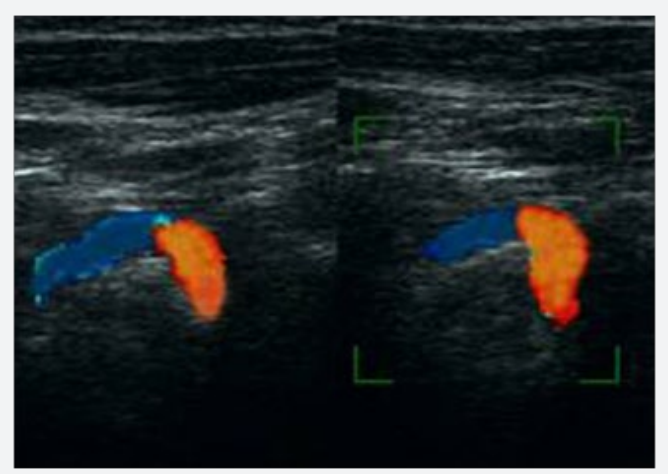

Figure 3: Visualization of the third segment of the normal vertebral artery.

In all subjects, the Doppler blood flow spectrum was recorded in the second segment (at level of C4-C5), at the third (at level of lateral atlanto-axial junction) and fourth segments of vertebral artery in the neutral spine position and also with the head turning to the side. In the control group in the second segment of the VA, Vs was $50.3 \pm 5.1 \mathrm{~cm} / \mathrm{s}$, RI-0.61 \pm 0.03 ; at the level of 3 -rd segment $-48.9 \pm 5.1 \mathrm{~cm} / \mathrm{s}$, RI $-0.58 \pm 0.03$; at the rotation of the head - Vs $43.6 \pm 4.5 \mathrm{~cm} / \mathrm{s}, \mathrm{RI}-0.62 \pm 0.03$, respectively (Figure 1-5).

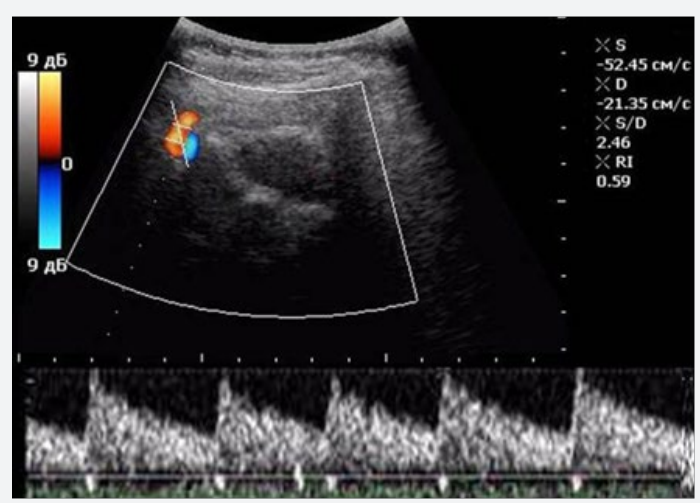

Figure 4: Doppler spectrum of the blood flow in the third segment of the vertebral artery in a patient of control group at a rotation of the head. The Vs is $52.45 \mathrm{~cm} / \mathrm{c}$, RI -0.59 .

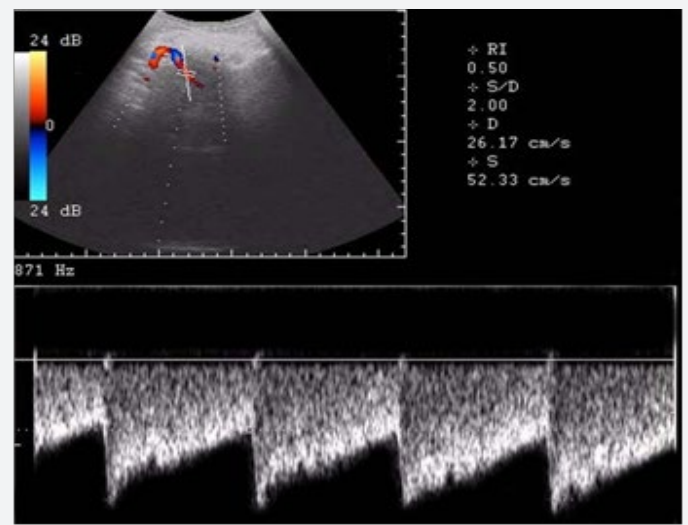

Figure 5: Doppler spectrum of the blood flow in the fourth segment of the vertebral artery in a patient of control group. The $\mathrm{Vs}$ is $52.33 \mathrm{~cm} / \mathrm{c}, \mathrm{RI}$ is normal 0.50 .

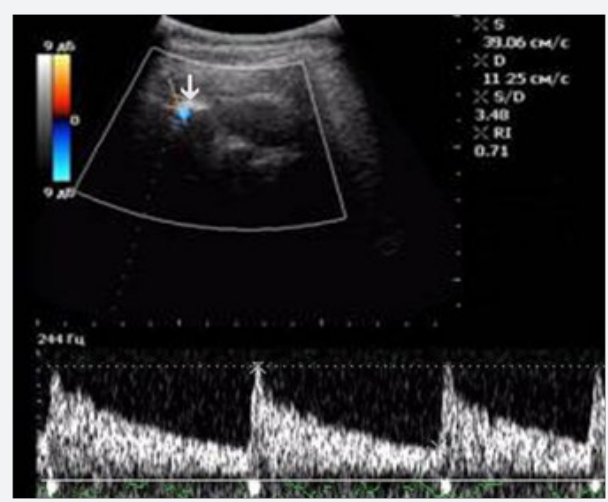

Figure 6: Doppler spectrum of the blood flow in third segment of the vertebral artery in a patient with arthrosis of the lateral atlanto-axial junction at a flexion of the neck. The RI is increased (0.71). The arrow show the reduced diameter of vertebral artery and osteofitis of the atlanto-axial junction. 
As can be seen from Table 1 in a patients with Atlanto-axial arthrosis in the second segment of the VA, Vs was $48.9 \pm 5.3 \mathrm{~cm} / \mathrm{s}$, RI-0.56 \pm 0.03 ; at the level of 3 -rd segment $45.3 \pm 4.9 \mathrm{~cm} / \mathrm{s}$, RI-0.54 \pm 0.03 ; at the rotation of the head- $37.2 \pm 4.1 \mathrm{~cm} / \mathrm{c}$, RI-
$0.71 \pm 0.04$ respectively (Figure 6). RI in patients with arthrosis of the atlas-axial junction with rotation of the neck was significantly less than in the second segment in these patients, and VS less than in the control group $(\mathrm{P}<0,05)$.

Table 1: Doppler parameters in patients with arthrosis of the atlanto-axial junction.

\begin{tabular}{|c|c|c|c|c|c|c|}
\hline \multirow{2}{*}{$\begin{array}{c}\text { Doppler } \\
\text { Parameters }\end{array}$} & \multicolumn{3}{|c|}{ Patients with Atlanto-axial arthrosis $(n=26)$} & \multicolumn{3}{|c|}{ Control group $(n=27)$} \\
\hline & II Segment of VA 1 & III Segment of VA 2 & Head Rotated 3 & $\begin{array}{l}\text { II Segment of } \\
\text { VA } 1\end{array}$ & $\begin{array}{l}\text { III Segment of } \\
\text { VA } 2\end{array}$ & Head rotated 3 \\
\hline \multirow{2}{*}{ Vs $(\mathrm{cm} / \mathrm{c})$} & \multirow{2}{*}{$48.9 \pm 5.3$} & \multirow{2}{*}{$45.3 \pm 4.9$} & $37.2 \pm 4.1$ & \multirow{2}{*}{$50.3 \pm 5.1$} & \multirow{2}{*}{$48.9 \pm 5.1$} & \multirow{2}{*}{$43.6 \pm 4.5$} \\
\hline & & & $\mathrm{P} 4-4<0.05$ & & & \\
\hline \multirow{3}{*}{ RI } & \multirow{3}{*}{$0.56 \pm 0.03$} & \multirow{3}{*}{$0.54 \pm 0.03$} & $0.71 \pm 0.04$ & \multirow{3}{*}{$0.61 \pm 0.03$} & \multirow{3}{*}{$0.58 \pm 0.03$} & \multirow{3}{*}{$0.62 \pm 0.03$} \\
\hline & & & $\mathrm{P} 4-1<0,05$ & & & \\
\hline & & & $\mathrm{P} 4-4<0.05$ & & & \\
\hline
\end{tabular}

Table 2: Doppler parameters in patients with instability of the atlanto-axial junction.

\begin{tabular}{|c|c|c|c|c|c|c|}
\hline \multirow[t]{2}{*}{ Doppler parameters } & \multicolumn{4}{|c|}{ Patients with Atlanto-axial Arthrosis $(n=26)$} & \multicolumn{2}{|c|}{ Control Group $(n=27)$} \\
\hline & $\begin{array}{l}\text { II Segment of } \\
\text { VA } 1\end{array}$ & $\begin{array}{l}\text { III Segment of } \\
\text { VA } 2\end{array}$ & Head Rotated 3 & $\begin{array}{l}\text { II Segment of } \\
\text { VA } 1\end{array}$ & $\begin{array}{l}\text { III Segment of } \\
\text { VA } 2\end{array}$ & Head Rotated 3 \\
\hline \multirow{2}{*}{ Vs $(\mathrm{cm} / \mathrm{c})$} & \multirow{2}{*}{$49.2 \pm 5.1$} & \multirow{2}{*}{$46.1 \pm 4.8$} & $34.1 \pm 4.2$ & \multirow{2}{*}{$50.3 \pm 5.1$} & \multirow{2}{*}{$48.9 \pm 5.1$} & \multirow{2}{*}{$43.6 \pm 4.5$} \\
\hline & & & $\mathrm{P} 4-4<0,05$ & & & \\
\hline \multirow{3}{*}{ RI } & \multirow{3}{*}{$0.59 \pm 0.03$} & \multirow{3}{*}{$0.58 \pm 0.03$} & $0.69 \pm 0.04$ & \multirow{3}{*}{$0.61 \pm 0.03$} & \multirow{3}{*}{$0.58 \pm 0,03$} & \multirow{3}{*}{$0.62 \pm 0.03$} \\
\hline & & & $\mathrm{P} 4-1<0.05$ & & & \\
\hline & & & $\mathrm{P} 4-4<0.05$ & & & \\
\hline
\end{tabular}

Dopplerometric parameters of vertebral artery blood flow in patients with atlanto-axial instability are presented in (Table 2). In this patients at the level of C5-C6, Vs amounted to $49.2 \pm 5.1 \mathrm{~cm} / \mathrm{s}, \mathrm{RI}-0.59 \pm 0.03$; at the level of $3-\mathrm{d}$ segment of VA-Vs was $46.1 \pm 4.8 \mathrm{~cm} / \mathrm{s}, \mathrm{RI}-0.58 \pm 0.03$ (Figure 7 ). When the head was turned to the side in patients with instability of the atlanto-axial junction, Vs was significantly lower compared to the control group $(34.1 \pm 4.2 \mathrm{~cm} / \mathrm{s}$ and $43.6 \pm 4.5 \mathrm{~cm} / \mathrm{s}$; RI more then in the second segment of the VA $(\mathrm{P}<0.05)$.

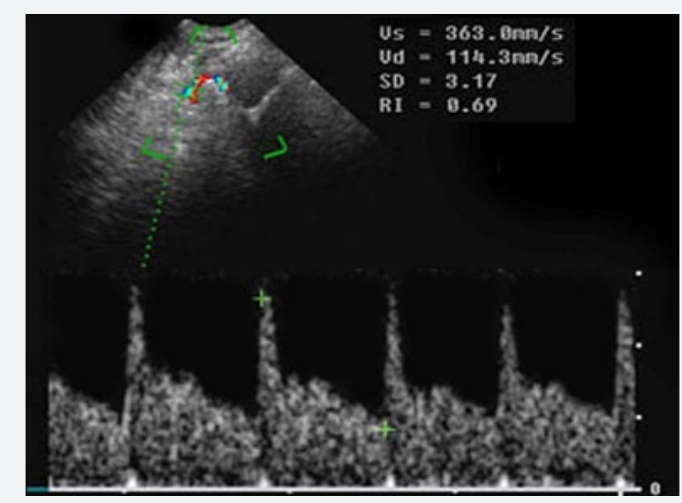

Figure 7: Doppler spectrum of the normal blood flow in the second segment of the vertebral artery at the level of C5-C6. The Vs is $48.7 \mathrm{~cm} / \mathrm{c}, \mathrm{RI}-0.58$.

\section{Discussion}

Bayrak et al. [10] studied correlations between the indices of degeneration, the positions of the cervical vertebrae and the Doppler parameters of the vertebral arteries. However, they evaluated vertebral arteries in patients with a head in a neutral position. Rotational Vertebral Artery Occlusion (RVAO), or bow hunter's syndrome, most often occurs at the C1-C2 level on physiological head rotation. It presents with symptoms of vertebrobasilar insufficiency [11]. Yamaoka Y [12] studied the role of ultrasound in diagnosing the degree of changes in the Atlanta loop with the maximum rotation of the head.

In our study, we assessed vertebral arteries in patients with arthrosis and instability of the atlas-axial junction and healthy with a turn of the head to the contralateral side. Because the vertebral artery passes through the bony transverse foramina, it is vulnerable to stenosis with head rotation caused by compression by osteophytes. Therefore, our results suggest that with the rotation of the unstable atlanto-axial junction compression increases, causing marked luminal narrowing and reducing blood flow through the vertebral arteries.

\section{Conclusion}

Instability of atlanto-axial junction, especially in combination with arthrosis, is one of the common causes of cervicogenic headache in young people. The main pathogenetic mechanism of the onset of pain is changes in blood flow in the third segment of the vertebral arteries, especially during rotational movements.

\section{References}

1. Biondi DM (2005) Cervicogenic headache: a review of diagnostic and treatment strategies. J Am Osteopath 105(4 Suppl 2): 16S-22S. 
2. (2013) Headache Classification Subcommittee of the International Headache Society. The International Classification of Headache Disorders. (3 ${ }^{\text {rd }}$ edn) (beta version). Cephalalgia 33(9): 629-808.

3. Antonaci F, Sjaastad O (2011) Cervicogenic Headache: a real headache. Curr Neurol Neurosci Rep 11(2): 149-155.

4. Hall T, Briffa K, Hopper D (2008) Clinical evaluation of cervicogenic headache: a clinical perspective. J Man Manip Ther 16(2): 73-80.

5. Yu X, Liu M, Meng L, Xiang L (2015) Classifying cervical spondylosis based on X-ray quantitative diagnosis. Journal 165(C): 222-227.

6. Mitchell J, Kramschuster K (2008) Real-time ultrasound measurements of changes in suboccipital vertebral artery diameter and blood flow velocity associated with cervical spine rotation. Physiother Res Int 13(4): 241-254

7. Abdullaiev R Ya, Marchenko VG, Dzyak LA (2010) Ultrasonography in Neurology. Kharkov: Nove word pp. 152.
8. Mitchell B, LeFebvre R (2013) Cervicogenic headache: assessment (includes general assessment of headaches) p. 68.

9. Zenkevich AS, Filatova EG, Latysheva NV (2016) Migraine and neck pain: Mechanisms of comorbidity. Neurology, Neuropsychiatry, Psychosomatics 8(1): 29-34.

10. Bayrak IK, Durmus D, Bayrak AO (2009) Effect of cervical spondylosis on vertebral arterial flow and its association with vertigo. Clin Rheumatol 28(1): 59-64.

11. Buchanan CC, McLaughlin N, Lu DC, Martin NA (2014) Rotational vertebral artery occlusion secondary to adjacent-level degeneration following anterior cervical discectomy and fusion. J Neurosurg Spine 20(6): 714-721.

12. Yamaoka Y, Ichikawa Y, Morita A (2015) Evaluation of rotational vertebral artery occlusion using ultrasound facilitates the detection of arterial dissection in the atlas loop. J Neuroimaging 25(4): 647-651.

\section{Your next submission with Juniper Publishers will reach you the below assets}

- Quality Editorial service

- Swift Peer Review

- Reprints availability

- E-prints Service

- Manuscript Podcast for convenient understanding

- Global attainment for your research

- Manuscript accessibility in different formats ( Pdf, E-pub, Full Text, Audio)

- Unceasing customer service

Track the below URL for one-step submission https://juniperpublishers.com/online-submission.php 